\title{
DIVISION XII/COMMISSION 14/WORKING GROUP ON MOLECULAR DATA
}

\author{
CHAIR \\ VICE-CHAIR \\ VICE-CHAIR
}

\author{
Steven R. Federman \\ Peter F. Bernath \\ Holger S. P. Müller
}

\section{TRIENNIAL REPORT 2009-2012}

\section{Introduction}

The current report covers the period from the second half of 2003 to the first half of 2011, bringing the Working Group's efforts up to date, and is divided into three main sections covering rotational, vibrational, and electronic spectroscopy. Rather than being exhaustive, space limitations only allow us to highlight a representative sample of work on molecular spectra. Related research on collisions, reactions on grain surfaces, and astrochemistry appear in the report by another Working Group. These also recount recent conferences and workshops on molecular astrophysics.

\section{Rotational Spectra}

A large number of reviews have appeared dealing with rotational spectra of molecules potentially relevant to radio-astronomical observations. Therefore, emphasis is placed on investigations dealing with molecular species already observed in space. Related molecules are included to a large extent also. The following groups have been created - hydride species, anions, molecules which may occur in circumstellar envelopes of late type stars, complex molecules, weed species, and other molecules - and are discussed in turn.

Several databases provide rotational spectra of molecular species of astrophysical and astrochemical relevance. The two most important sources for predictions generated from experimental data by employing appropriate Hamiltonian models are the Cologne Database for Molecular Spectroscopy, CDMS (http://www.astro.uni-koeln.de/ cdms/) with its catalog (http://www.astro.uni-koeln.de/cdms/catalog). An updated description appeared in Müller et al. (2005) and the JPL catalog (http://spec.jpl.nasa.gov/). Both also provide primary information, i.e. laboratory data with uncertainties, mostly in special archive sections. Additional primary data are available in the Toyama Microwave Atlas (http://www.sci.u-toyama.ac.jp/phys/4ken/atlas/). A useful resource on the detection of certain molecular transitions in space is the NIST Recommended Rest Frequencies for Observed Interstellar Molecular Microwave Transitions, which has been updated and described by Lovas (2004).

The European FP7 project Virtual Atomic and Molecular Data Centre, VAMDC, (http://www.vamdc.org/) aims at combining several spectroscopic, collisional, and kinetic databases. The CDMS is the rotational spectroscopy database taking part; several infrared databases are also involved. The project has been described by Dubernet et al. (2010). Other tertiary sources combining data from various databases are, e.g., Cassis 
(http://cassis.cesr.fr/), which provides tools to analyze astronomical spectra, or splatalogue (http://www.splatalogue.net/).

\subsection{Hydrides}

Hydrides here are all molecules consisting of one non-metal atom and one or more $\mathrm{H}$ atoms. They may be neutral or positively charged. Metal hydrides will be dealt with in subsection 2.3. Rotational spectra of some anionic hydride molecules have been obtained also, but such molecules have not yet been detected in space, see also subsection 2.2. Hydrides are usually difficult to observe from the ground as their fundamental transitions occur in the upper millimeter region for heavier species to the terahertz region for lighter ones. Some hydrides have recently been detected from the ground, such as ${ }^{13} \mathrm{CH}^{+}$with the $\mathrm{CSO}$, or $\mathrm{SH}^{+}$and $\mathrm{OH}^{+}$with the APEX telescope. The launch of the Herschel satellite in May 2009 has created a wealth of opportunities to investigate hydrides, in particular with the high resolution instrument HIFI. $\mathrm{H}_{2} \mathrm{O}^{+}, \mathrm{H}_{2} \mathrm{Cl}^{+}, \mathrm{ND}$, and possibly $\mathrm{HCl}^{+}$have been deteceted, and the fundamental transitions of $\mathrm{CH}^{+}$and of $\mathrm{HF}$ have been observed for the first time.

The very light hydrides $\mathrm{H}_{2} \mathrm{D}^{+}$and $\mathrm{HD}_{2}^{+}$have attracted considerable attention (Amano \& Hirao 2005; Asvany et al. 2008; Yonezu et al. 2009). Particularly noteworthy is the measurement of the $1_{0,1}-0_{0,0}$ transition of $\mathrm{H}_{2} \mathrm{D}^{+}$more than $60 \mathrm{MHz}$ away from the previously accepted value by Asvany et al. (2008). A similarly large deviation occurred between the initial transition frequency of the $J=1-0$ transition of $\mathrm{CH}^{+}$(Pearson \& Drouin 2006) and the one measured by Amano (2010a), who also recorded the same transition for ${ }^{13} \mathrm{CH}^{+}$and $\mathrm{CD}^{+}$. Müller (2010) used the latter transition frequencies together with data from electronic spectra to derive extensive predictions for rotational and rovibrational transitions of several $\mathrm{CH}^{+}$isotopologues. Isotopic $\mathrm{CH}$ (Halfen et al. 2008), $\mathrm{CH}_{2}$ (Brünken et al. 2005), CHD (Ozeki et al. 2011), $\mathrm{CH}_{2} \mathrm{D}^{+}$(Amano 2010b), and $\mathrm{CH}_{3} \mathrm{D}$ (Drouin et al. 2009) have been other carbon containing hydrides studied.

No accurate rotational transition frequencies are available for $\mathrm{CH}_{2}^{+}$or $\mathrm{NH}_{2}^{+}$. Their fundamental transitions are beyond the region which can be studied with HIFI.

The nitrogen hydrides NH (Flores-Mijangos et al. 2004), $\mathrm{NH}^{+}$(Hübers et al. 2009), $\mathrm{NH}_{3}$ (Yu et al. 2010), as well as the isotopologues $\mathrm{NHD}_{2}$ (Endres et al. 2006), ${ }^{15} \mathrm{NH}_{2} \mathrm{D}$ and ${ }^{15} \mathrm{NHD}_{2}$ (Elkeurti et al. 2008) have been investigated recently. Transition frequencies have been determined for the oxygen hydrides ${ }^{17} \mathrm{OH}$ (Polehampton et al. 2003), $\mathrm{OH}^{+}$ (Müller et al. 2005), $\mathrm{H}_{2} \mathrm{O}$ and $\mathrm{H}_{2}{ }^{18} \mathrm{O}$ (Golubiatnikov et al. 2006), $\mathrm{H}_{2}{ }^{17} \mathrm{O}$ (Puzzarini et al. 2009), $\mathrm{D}_{2} \mathrm{O}$ (Brünken et al. 2007a; Cazzoli et al. 2010a), $\mathrm{H}_{3} \mathrm{O}^{+}$(Yu et al. 2009), and $\mathrm{H}_{2} \mathrm{DO}^{+}$(Müller et al. 2010).

Halogen containing molecules have attracted increased attention in recent years. Among the hydride species investigated recently are DF (Cazzoli et al. 2006a), $\mathrm{HF}^{+}$(Allen et al. 2004), $\mathrm{H}_{2} \mathrm{~F}^{+}$(Fujimori et al. 2011), and $\mathrm{H}_{2} \mathrm{Cl}^{+}$(Araki et al. 2001).

Other investigations of heavier hydrides include Lamb-dip measurements of low-lying rotational states of $\mathrm{PH}_{3}$ (Cazzoli \& Puzzarini 2006) and a combined analysis of spectroscopic data of $\mathrm{SH}^{+}$(Brown \& Müller 2009).

\subsection{Anions}

There had been speculation about the possibility of molecular anions in space for quite a while. However, accurate transition frequencies were only known for $\mathrm{OH}^{-}$and $\mathrm{SH}^{-}$; for a few other species approximate values were known from infrared spectroscopy. However, all these species were deemed to be too fragile with respect to photolysis. Moreover, all these species were hydride species with fundamental transitions not easily accessible from the ground. 
Interestingly, a molecular line survey of the circumstellar envelope of the carbon-rich star CW Leo, also known as IRC +10216, between 28 and $50 \mathrm{GHz}$ revealed several series of unidentified lines (Kawaguchi et al. 1995). One of these turned out to be caused by the anion $\mathrm{C}_{6} \mathrm{H}^{-}$(McCarthy et al. 2006). This finding sparked a flurry of investigations into laboratory rotational spectra of related molecular anions and the search for these species in space. $\mathrm{C}_{2} \mathrm{H}^{-}$(Brünken et al. 2007b), as well as $\mathrm{C}_{4} \mathrm{H}^{-}$and $\mathrm{C}_{8} \mathrm{H}^{-}$(Gupta et al. 2007), were characterized and, except for the smallest member, found in space. The isoelectronic molecules $\mathrm{CN}^{-}$(Gottlieb et al. 2007) and $\mathrm{C}_{3} \mathrm{~N}^{-}$(Thaddeus et al. 2008) were found in the lab as well as in the circumstellar envelope of CW Leo. The identification of $\mathrm{C}_{5} \mathrm{~N}^{-}$also in that source seemed to be certain enough even in the absence of laboratory spectral data. Furthermore, submillimeter transitions have been recorded for $\mathrm{CN}^{-}, \mathrm{C}_{2} \mathrm{H}^{-}$, and $\mathrm{C}_{4} \mathrm{H}^{-}$(Amano 2008) as well as for $\mathrm{C}_{3} \mathrm{~N}^{-}$(Amano 2010c). In addition, the laboratory rotational spectrum of $\mathrm{NCO}^{-}$was recently reported (Lattanzi et al. 2010).

\subsection{Circumstellar molecules}

The chemistry of circumstellar envelopes of late-type stars is special as a number of molecules have only been detected or are particularly abundant in such sources. Probably the most fascinating object in this regard is CW Leo. Whereas many astronomers have thought this source has a rather special chemistry, it turned out that it is a rather common source. The reason why molecules are particularly easily detected in this source is its proximity. For instance, several metal containing molecules have been detected first in the envelope of $\mathrm{CW}$ Leo, but in recent years $\mathrm{MgNC}, \mathrm{NaCN}$, and $\mathrm{NaCl}$ have been detected also in the envelopes of other AGB stars, the latter even in those of O-rich AGB stars such as IK Tau and VY CMa. Interestingly, recently the metal-containing molecules $\mathrm{AlO}$ and $\mathrm{AlOH}$ as well as PO have been detected first in the envelope of VY CMa. In addition, KCN and FeCN were detected toward CW Leo.

For a number of metal-containing molecules rotational spectra have been studied. Hydride species include AlH (Halfen \& Ziurys 2004), CrH (Harrison et al. 2006), MnH (Halfen \& Ziurys 2008), and FeH (Brown et al. 2006). Among the nitride and oxide species studied are VN and VO (Flory \& Ziurys 2008), CoO (McLamarrah et al. 2005), $\mathrm{ZnO}$ (Zack et al. 2009), and even $\mathrm{TiO}_{2}$ (Kania et al. 2011). Several halogenides have been investigated, such as $\mathrm{NaCl}$ and $\mathrm{KCl}$ (Caris et al. 2004), TiF (Sheridan et al. 2003), $\mathrm{TiCl}$ (Maeda et al. 2001), $\mathrm{VCl}$ (Halfen et al. 2009b), CoF (Harrison et al. 2007), CoCl (Flory et al. 2004), ZnF (Flory et al. 2006), and ZnCl (Tenenbaum et al. 2007). Also recorded were rotational spectra of $\mathrm{CoCN}$ and NiCN (Sheridan et al. 2004; Sheridan \& Ziurys 2003).

The study of the rotational spectrum of $\mathrm{C}_{2} \mathrm{P}$ (Halfen et al. 2009a) laid the ground work for its detection in the circumstellar envelope of $\mathrm{CW}$ Leo. This detection, in turn, suggests that molecules such as $\mathrm{C}_{2} \mathrm{~F}, \mathrm{C}_{2} \mathrm{Cl}, \mathrm{C}_{3} \mathrm{~F}$, and $\mathrm{C}_{3} \mathrm{Cl}$ may be detectable as well. Rotational spectra have been detected for all of these species except for the first one (Sumiyoshi et al. 2003; Yoshikawa et al. 2009b,a).

Other molecules investigated, including predominantly or potentially circumstellar ones, are $\mathrm{C}_{2} \mathrm{H}$ and $\mathrm{C}_{6} \mathrm{H}$ in excited vibrational states (Killian et al. 2007; Gottlieb et al. 2010) and $\mathrm{CH}_{3} \mathrm{CP}$ (Bizzocchi et al. 2003).

\subsection{Complex molecules}

Some of the smaller complex molecules with many emission or absorption lines observable by radio-astronomical means are presented in subsection 2.5.

Among the larger saturated or almost saturated molecules, propenal, propanal, and acetamide have been detected with the GBT in the microwave region. Interestingly, 
propylene has been detected with the IRAM $30 \mathrm{~m}$ telescope toward TMC-1. Three complex molecules have been detected with the same instrument in the course of a molecular line survey of Sagittarius B2(N) at $3 \mathrm{~mm}$. These are aminoacetonitrile, $n$-propyl cyanide, and ethyl formate. The detection articles also feature critical evaluations of the spectroscopic parameters of the former two molecules (Belloche et al. 2008, 2009). The rotational spectrum of ethyl formate has also been revisited (Medvedev et al. 2009). Other studies include cyclo-propyl cyanide (Bizzocchi et al. 2008) and iso-propyl cyanide (Müller et al. 2011), two conformers of ethylene glycol (Christen \& Müller 2003; Müller \& Christen 2004), microwave spectra of several conformers of 1,2- and 1,3-propanediol (Lovas et al. 2009; Plusquellic et al. 2009), propane (Drouin et al. 2006), millimeter wave spectra of the amino acids glycine and alanine (Ilyushin et al. 2005; Hirata et al. 2008), acetamide (Ilyushin et al. 2004), methylamine (Ilyushin \& Lovas 2007), acetic acid (Ilyushin et al. 2008), n-propanol (Kisiel et al. 2010), and diethyl ether (Walters et al. 2009). Other investigations may turn out to also be relevant once telescope arrays such as EVLA, NOEMA, or ALMA conduct large scale line surveys or dedicated seaches for particular molecules.

\subsection{Weed species}

The term "weed species" has been coined for molecules that have very many emission or absorption lines in various sources, but considered mostly for star-forming regions. It should be emphasized that the plethora of lines is not only a nuisance, but there is also considerable information about, for example, temperature or density in these lines. The molecule with particularly many rather strong lines is methanol. It has been extensively studied up to the second torsional state ( $\mathrm{Xu}$ et al. 2008); even higher states have been studied to some extent (Pearson et al. 2009), but these are difficult to model at present. $\mathrm{CH}_{3} \mathrm{OH}$ has also been proposed as a particularly well suited molecule to investigate the possibility of temporal or spatial variations of fundamental constants (Jansen et al. 2011; Levshakov et al. 2011). One requirement is the knowledge of very highly accurate transition frequencies. Some of these have been summarized as well as newly reported ones by Müller et al. (2004). Other methanol isotopologues studied recently include $\mathrm{CH}_{2} \mathrm{DOH}$ (Mukhopadhyay et al. 2002; Lauvergnat et al. 2009), $\mathrm{CH}_{3} \mathrm{OD}$ (Duan et al. 2003), and $\mathrm{CH}_{3}{ }^{18} \mathrm{OH}$ (Fisher et al. 2007).

Other weed molecules, for which several isotopic species have been investigated, are methyl cyanide (Müller et al. 2009), ethyl cyanide (Brauer et al. 2009; Demyk et al. 2007; Margulès et al. 2009b), vinyl cyanide (Kisiel et al. 2009), methyl formate (Ilyushin et al. 2009; Carvajal et al. 2009, 2010; Margulès et al. 2009a, 2010), formamide (Kryvda et al. 2009), and acetone (Groner et al. 2008; Lovas \& Groner 2006). Moreover, dimethyl ether (Endres et al. 2009), its isomer ethanol (Pearson et al. 2008), and the only inorganic weed species $\mathrm{SO}_{2}$ (Müller \& Brünken 2005) have been studied.

One should keep in mind that weed species are not only seen in the ground vibrational state, but often in several excited states, and this is true for minor isotopic species as well. While deriving an appropriate Hamiltonian model is usually the most compact form to represent the rotational spectrum of a molecule in a given vibrational state, this task can be formidable and worse in cases of strong vibration-rotation interaction that may take much more than months to be tackled. As an alternative, the De Lucia group proposed recording spectra at different temperatures. While this procedure yields huge amounts of data, and extrapolation in frequency or to higher temperatures is impossible and extrapolation to lower temperatures only to some extent, it seems to be still a pragmatic approach for some molecules. Several reports have been published on ethyl cyanide (Fortman et al. 2010) and one on vinyl cyanide (Fortman et al. 2011). 


\subsection{Other molecules}

Other molecules, for which rotational spectra have been (re-) investigated, include cations such as $\mathrm{HCNH}^{+}$and $\mathrm{CH}_{3} \mathrm{CNH}^{+}$(Amano et al. 2006), $\mathrm{CS}^{+}$(Bailleux et al. 2008), $\mathrm{CF}^{+}$ (Cazzoli et al. 2010b), ${ }^{15} \mathrm{~N}$ isotopologues of $\mathrm{N}_{2} \mathrm{H}^{+}$(Dore et al. 2009), $\mathrm{HCS}^{+}$(Margulès et al. 2003), and $\mathrm{HCO}^{+}$(Tinti et al. 2007).

Other short-lived molecules include DNC (Brünken et al. 2006), $\mathrm{C}_{3} \mathrm{H}$ and ${ }^{13} \mathrm{C}$ isotopologues of $\mathrm{C}_{n} \mathrm{H}$ with $n=3,5-7$ (Caris et al. 2009; McCarthy \& Thaddeus 2005), HOCN, HONC, and HSCN (Brünken et al. 2009a; Mladenović et al. 2009; Brünken et al. 2009b) as well as SiN and PN (Bizzocchi et al. 2006; Cazzoli et al. 2006b).

In addition, several stable or fairly stable molecules have been studied, including isotopologues of CO in their ground vibrational states (Puzzarini et al. 2003) and the main isotopologue in excited vibrational states (Gendriesch et al. 2009), various isotopologues in the ground and excited states of CS and SiS (Müller et al. 2005, 2007), isotopologues of $\mathrm{HCN}$ in their ground vibrational states (Cazzoli \& Puzzarini 2005) and the main isotopologue in excited vibrational states (Zelinger et al. 2003), $\mathrm{H}_{2} \mathrm{CO}$ (Brünken et al. 2003), the isoelectronic $\mathrm{H}_{2} \mathrm{CNH}$ (Dore et al. 2010), $\mathrm{H}_{2} \mathrm{CS}$ (Maeda et al. 2008), isotopologues of $\mathrm{HCOOH}$ (Lattanzi et al. 2008), and $\mathrm{CH}_{3} \mathrm{C}_{2} \mathrm{H}$ and $\mathrm{CH}_{3} \mathrm{C}_{4} \mathrm{H}$ (Cazzoli \& Puzzarini 2008).

\section{Vibrational Spectra}

Here we describe vibration-rotation spectra of gaseous molecules of astronomical or potential astronomical interest. It is based in part on a review article entitled "Molecular astronomy of cool stars and sub-stellar objects" aimed at physical chemists and laboratory spectroscopists (Bernath 2009).

In addition to the references to particular molecules given below there are a number of spectral database compilations that are useful. Perhaps the most helpful is the HITRAN database that contains vibration-rotation line parameters for a large number of species such as $\mathrm{H}_{2} \mathrm{O}, \mathrm{CO}_{2}, \mathrm{CO}$, etc. found in the Earth's atmosphere (Rothman et al. 2009). HITRAN is widely used for astronomical applications although it is not always suitable because of missing lines and bands, particularly in the near infrared region. For example, "cool" astronomical objects such as brown dwarfs can have surface temperatures in excess of $1000 \mathrm{~K}$, and HITRAN is designed for temperatures near $300 \mathrm{~K}$. In this regard, there is a HITEMP database (Rothman et al. 2010) for $\mathrm{H}_{2} \mathrm{O}, \mathrm{CO}_{2}, \mathrm{CO}, \mathrm{NO}$, and $\mathrm{OH}$ that is more suitable for high temperature sources such as stellar atmospheres.

For larger molecules, individual vibration-rotation lines are no longer clearly resolved and it becomes necessary to replace line-by-line calculations by absorption cross sections. The main drawback to using cross sections is that a considerable number of laboratory measurements are needed to match the temperature and pressure conditions of the objects under observation. HITRAN also includes a number of high resolution infrared absorption cross sections for organic molecules such as ethane and acetone, but the broadening gas in HITRAN is air rather than $\mathrm{H}_{2}, \mathrm{~N}_{2}$, or $\mathrm{CO}_{2}$. While the GEISA database has significant overlap with HITRAN, it contains additional molecules of interest for studies of planetary atmospheres (Jacquinet-Husson et al. 2011). A very useful set of infrared absorption cross sections for several hundred molecules have been measured at the Pacific Northwest National Laboratory (PNNL) for the $600-6500 \mathrm{~cm}^{-1}(1.54-16.7 \mu \mathrm{m})$ range (Sharpe et al. 2004). The PNNL IR database, however, may not be completely suitable for astronomical applications, for example for planetary atmospheres. All PNNL spectra are recorded at relatively low resolution $\left(0.112 \mathrm{~cm}^{-1}\right)$ as mixtures with pure nitrogen gas at pressures of 760 Torr and temperatures of 278, 293, or $323 \mathrm{~K}$. Nevertheless, in the 
absence of spectra recorded under more appropriate experimental conditions, they can be very useful.

Other interesting general sources for infrared data are various high resolution spectral atlases of the Sun (Livingston \& Wallace 2003; Hase et al. 2010) and sunspots (Wallace et al. 2001, 2002) because they include molecular (and atomic) line assignments. The web site spectrafactory (Cami et al. 2010a) is also useful for calculating infrared spectra of astronomical interest, although not all of the input line parameters are the most recent or recommended ones.

\subsection{Diatomic Molecules}

Diatomic molecules, particularly diatomic hydrides of the more abundant elements, are often observed through their infrared spectra. Molecular hydrogen itself is difficult to observe in the infrared because all transitions are electric-dipole forbidden; however, HD has a small dipole moment and very recently the 2-0 band was measured near $1.4 \mu \mathrm{m}$ by cavity ring down spectroscopy (Kassi \& Campargue 2011). In the case of $\mathrm{OH}, \mathrm{NH}$, and $\mathrm{CH}$, the new infrared solar atlas (Hase et al. 2010) measured by the Atmospheric Chemistry Experiment (ACE) infrared Fourier transform spectrometer from orbit (Bernath et al. 2005) has led to an improvement in the spectroscopy. The infrared Fraunhofer lines were combined with laboratory measurements to extend the measured line positions to higher vibrational and rotational quantum numbers for $\mathrm{OH}$ (Bernath \& Colin 2009), NH (Ram \& Bernath 2010), and CH (Colin \& Bernath 2010).

Laboratory vibration-rotation spectra for a considerable number of metal hydrides are known with recent measurements of, for example, BeH (Shayesteh et al. 2003a), MgH (Shayesteh et al. 2004a), and $\mathrm{CaH}$ (Shayesteh et al. 2004b); even the metal dihydrides $\mathrm{BeH}_{2}$ (Shayesteh et al. 2003b) and $\mathrm{MgH}_{2}$ (Shayesteh et al. 2003c) have been detected in the laboratory. Although metal hydrides such as $\mathrm{MgH}$ and $\mathrm{CaH}$ are detected in stellar atmospheres by their electronic transitions, there have been no infrared astronomical observations. Other diatomics such as $\mathrm{CO}, \mathrm{SO}, \mathrm{SiO}, \mathrm{HF}, \mathrm{HCl}, \mathrm{SH}, \mathrm{CS}$, and $\mathrm{SiS}$ are commonly seen by infrared observations of cool stellar atmospheres (Bernath 2009); their spectroscopy however has not been improved much in recent years. An exception to this is some work on the line intensities of SiS (Cami et al. 2009) and $\mathrm{HCl}$ ( $\mathrm{Li}$ et al. 2011).

\subsection{Small Polyatomics}

The spectra of "cold" water, ammonia, and methane as given in the HITRAN database are generally satisfactory for astronomical purposes, except for overtone and combination bands of $\mathrm{NH}_{3}$ and $\mathrm{CH}_{4}$ in the near infrared and visible regions. For spectra of hot samples as in brown dwarfs and exoplanets, the situation is much less sanguine, except in the case of water for which there has been extensive experimental (Zobov et al. 2008) and theoretical work (Barber et al. 2006). Much work is continuing on highly-excited water levels near dissociation and on computing line intensities ab initio, but the BT2 line list (Barber et al. 2006) is generally suitable for computing water opacities. For hot ammonia there has been rapid recent progress with new laboratory spectra recorded (Hargreaves et al. 2011) and with at least two groups providing rather good calculated spectra (Huang et al. 2011; Yurchenko et al. 2011). Ammonia is seen in brown dwarfs and is thought to be the key molecule in defining a new class of ultracool Y-type dwarfs (Cushing et al. 2011). Methane is the laggard because of the difficulty of the problem, and the existing experimental data (Nassar \& Bernath 2003) and calculations are not very satisfactory for simulating brown dwarf and exoplanet spectra. For $\mathrm{CO}_{2}$, HITRAN for cold molecules and HITEMP or CDSD-4000 databases (Tashkun \& Perevalov 2011) for hot molecules are recommended. 


\subsection{Large Molecules}

The discovery of $\mathrm{C}_{60}$ and $\mathrm{C}_{70}$ in the young planetary nebula Tc1 was reported by Cami et al. (2010b) using the Spitzer Space Telescope. The discovery was rapidly confirmed with detections in other planetary nebulae; some of these sources also have spectral features generally attributed to polycyclic aromatic hydrocarbons (PAHs). Infrared emission spectra of gaseous $\mathrm{C}_{60}$ and $\mathrm{C}_{70}$ were recorded as a function of temperature by Nemes et al. (1994) and more recently the integrated molar absorptivity of the infrared bands of the solid has been measured as a function of temperature (Iglesias-Groth et al. 2011). There have also been extensive laboratory measurements and quantum chemical calculations of PAH spectra, some of which is summarized in the NASA Ames database (Bauschlicher et al. 2010). Traditionally infrared spectra of neutral and ionized PAHs have been recorded by matrix isolation spectroscopy, but now gas-phase measurements are possible (Ricks et al. 2009; Galué et al. 2011). Computational studies of PAHs and related species have also advanced, and the quality and quantity of calculations available is remarkable (Hudgins et al. 2005; Bauschlicher et al. 2010).

\section{Electronic Spectra}

In this section we describe recent work on electronic spectra that includes line identification, energy levels, as well as data needed for photochemical models. The data come in a variety of forms, such as absorption cross sections (or equivalently oscillator strengths), predissociation widths, and analyses of line anomalies resulting from perturbations between energy levels. Here we can only present a representative sampling of work on electronic spectra. The number of experiments on electron excitation/scattering is great, and we provide a few illustrative examples of research in this area. This section is divided into three topics: interstellar matter, which includes diffuse molecular clouds and disks around newly formed stars as well as comets whose chemistry is similar, metal hydrides and oxides in the spectra of late-type stars, and the atmospheres of planets and their satellites. Recent attempts to identify the diffuse interstellar bands is not included, but instead we refer the reader to a review on laboratory astrophysics (Savin et al. 2011) that includes a discussion of this topic. It is worthwhile noting, however, that the study of the diffuse interstellar bands has led to a renaissance in the gas phase spectroscopy of complex carbon molecules that begun in 2003. A typical example is the case of PAH molecules. Traditionally UV-Visible spectra of neutral and ionized PAHs could only be recorded by matrix isolation spectroscopy, but now gas-phase measurements are possible (see reviews in Joblin \& Tielens (2011)).

\subsection{Interstellar matter}

There is continued interest in spectroscopic studies of $\mathrm{CO}$ and much of the recent efforts are needed for improved photochemical modeling. A comprehensive analysis of Rydberg states has been published (Eidelsberg et al. 2004a), as has a compilation of triplet and singlet transitions (Eidelsberg \& Rostas 2003) that included oscillator strengths. Improved wavelengths have appeared for the $A-X$ system of bands in $\mathrm{C}^{17} \mathrm{O}$ and $\mathrm{C}^{18} \mathrm{O}$ (Steinmann et al. 2003; du Plessis et al. 2006, 2007), for the $E-X(0,0)$ band in CO, ${ }^{13} \mathrm{CO}$, and ${ }^{13} \mathrm{C}^{18} \mathrm{O}$ (Cacciani \& Ubachs 2004), and for triplet-singlet bands involving the $e, d$, and $a^{\prime}$ states in several isotopologues (du Plessis et al. 2007; Yang et al. 2008; Dickenson et al. 2010). Several quantum mechanical calculations of potential energy curves (Chakrabarti \& Tennyson 2006; Vázquez et al. 2009; Lefebvre-Brion et al. 2010) have appeared. Empirical determinations of oscillator strengths for Rydberg transitions have been published, including one based on interstellar spectra acquired with the Far Ultraviolet Spectroscopic 
Explorer (Sheffer et al. 2003), two using synchrotron radiation (Eidelsberg et al. 2004b; Eidelsberg et al. 2006), and one employing electron scattering techniques (Kawahara et al. 2008). Gilijamse et al. (2007) have obtained the lifetime for the $a^{3} \Pi v=0$ level. In their study, Eidelsberg et al. (2006) have also reported predissociation rates for $B$ and $W$ states; the large rates found for the $B^{1} \Sigma^{+} v=6$ level result from interactions with the $D^{\prime}$ state. A number of other experimental and theoretical efforts describing the $B$ - $D^{\prime}$ interaction have been published (Andric et al. 2004; Grozdanov et al. 2004; Baker 2005a; Bitencourt et al. 2007). The triplet $k$ and $c$ states have been the focus of studies (Baker 2005b; Baker \& Launay 2005a,b,c) on perturbations caused with other states, while Ben et al. (2007) have described their experiment on perturbations between the $a$ and $d$ levels. Finally, a review (Lefebvre-Brion \& Lewis 2007) discussing perturbations in the isoelectronic molecules, $\mathrm{CO}$ and $\mathrm{N}_{2}$, has also appeared. More spectroscopic work on $\mathrm{N}_{2}$ is provided below.

New spectroscopic studies on $\mathrm{CH}, \mathrm{CH}^{+}, \mathrm{NH}$ have appeared since 2003. Extending the study of Watson (2001) on Rydberg transitions in CH, Sheffer \& Federman (2007) have inferred oscillator strengths and predissociation rates for the $3 d-X, 4 d-X, F-X$, and $D-X$ bands seen in interstellar spectra acquired with the Hubble Space Telescope. Theoretical efforts on $\mathrm{CH}$ include structure calculations of the $3 d$ complex (Vázquez et al. 2007) and oscillator strengths for Rydberg transitions (Lavín et al. 2009); the latter study also determined photoionization cross sections. A new analysis of the $A^{1} \Pi-X^{1} \Sigma^{+}$ system in $\mathrm{CH}^{+}$has been completed (Hakalla et al. 2006), and Weselak et al. (2009) have obtained oscillator strengths for the $(1,0),(2,0),(3,0)$, and $(4,0)$ bands of this system from ground-based interstellar spectra. $\mathrm{CH}^{+}$photodissociation cross sections have been a focus of recent theoretical work (Barinovs \& van Hemert 2004; Bouakline et al. 2005). Revised term values have been determined for the $X^{3} \Sigma^{-}$and $A^{3} \Pi$ states of $\mathrm{NH}$ by Ram \& Bernath (2010), who analyzed spectra from the ACE and ATMOS instruments.

Other molecules of interest to interstellar and cometary studies, such as $\mathrm{C}_{2}, \mathrm{CN}$, and $\mathrm{C}_{3}$, have been studied recently. Theoretical efforts have computed oscillator strengths and radiative lifetimes for singlet (Phillips) and triplet (Swan, Ballik-Ramsay, and $d-$ c) systems in $\mathrm{C}_{2}$ (Kokkin et al. 2007; Schmidt \& Bacskay 2007); of particular note is that a self-consistent set of oscillator strengths for the Phillips $(A-X)$ system of bands is emerging. Experimental studies involving triplet states have been performed with a variety of techniques (Joester et al. 2007; Tanabashi et al. 2007; Nakajima et al. 2009; Bornhauser et al. 2010, 2011), many times focusing on the presence of perturbations. Toffoli \& Lucchese (2004) have calculated near threshold photoionization cross sections for $\mathrm{C}_{2}$. Spectroscopic studies of the violet and red band systems for isotopologues of CN (Ram et al. 2006, 2010b,c) have improved the precision of the molecular constants for this molecule. This work will also be of interest to stellar astronomy. Shi et al. (2010) have obtained spectroscopic parameters in the isotopologues of $\mathrm{CN}$ through ab initio calculations. Moreover, experimental work on bands in the $A^{1} \Pi_{u}-X^{1} \Sigma_{g}^{+}$system of $\mathrm{C}_{3}$ has appeared (McCall et al. 2003; Tanabashi et al. 2005; Zhang et al. 2005; Chen et al. 2010, 2011). Perturbations have been seen in many of these bands. Zhang et al. (2005) have measured lifetimes as well.

Spectroscopic studies on $\mathrm{H}_{2} \mathrm{O}$ and $\mathrm{HCl}$ have also been conducted. Fillion et al. (2004) used synchrotron radiation to examine the intense Rydberg nd series in $\mathrm{H}_{2} \mathrm{O}$ for energies up to $12 \mathrm{eV}$. Another study with synchrotron radiation found several new vibrational progressions around $10 \mathrm{eV}$ and also reported abolute cross sections (Mota et al. 2005). Additional experimental efforts obtained absolute absorption cross sections with a synchrotron source (Cheng et al. 2004) and oscillator strengths via electron impactexcitation (Thorn et al. 2007); Cheng et al. (2004) compared their results with additional 
theoretical computations. Borges (2006b) extended his earlier calculations (Borges 2006a) in a study of oscillator strengths for the $\tilde{A}^{1} B_{1}-\tilde{X}^{1} A_{1}$ transition in $\mathrm{H}_{2} \mathrm{O}$. Another electron scattering experiment ( $\mathrm{Li}$ et al. 2006) derived oscillator strengths for valence-shell excitations in $\mathrm{HCl}$.

\subsection{Late-type stars}

The transition from metal oxides to metal hydrides is a signature of the latest stellar spectral types. During the reporting period papers on line lists, line strengths, and opacties have appeared. For metal hydrides, these studies include high-resolution spectra acquired with a Fourier transform spectrometer of bands in the $A^{2} \Pi-X^{2} \Sigma^{+}$and $B$ ${ }^{2} \Sigma^{+}-X^{2} \Sigma^{+}$systems of ${ }^{24} \mathrm{MgH}$ (Shayesteh et al. 2007) and of the $E^{2} \Pi-X^{2} \Sigma^{+}$ transition in $\mathrm{CaH}$ and $\mathrm{CaD}$ (Ram et al. 2011b). The work on $\mathrm{MgH}$ provided the data on the highest lying vibrational level in the ground electronic state. A deperturbation analysis of the $\mathrm{MgH}$ spectra was recently completed (Shayesteh \& Bernath 2011). Using laser-induced fluorescence, Chowdhury et al. (2006) examined the (1,0) band of the $A$ ${ }^{6} \Sigma^{+}-X^{6} \Sigma^{+}$transition in $\mathrm{CrH}$. New theoretical calculations have led to improved line lists and opacities for transitions in TiH (Burrows et al. 2005) and the $F^{4} \Delta_{i}-X^{4} \Delta_{i}$ transitions in $\mathrm{FeH}$ (Dulick et al. 2003). Magnetic properties of $\mathrm{FeH}$ involving the $F$ and $X$ states, including a study of the Zeeman effect, have been determined (Harrison et al. 2008; Harrison \& Brown 2008).

\subsection{Planetary atmospheres}

Nitrogen and sulfur dioxide have received a considerable amount of attention recently. Spectroscopic work on $\mathrm{N}_{2}$ (Sprengers et al. 2003, 2005b; Lewis et al. 2008a; Vieitez et al. 2008) has focused on extreme UV transitions, where perturbations and predissociation play a significant role; the study by Sprengers et al. (2003) considered the ${ }^{15} \mathrm{~N}_{2}$ and ${ }^{14} \mathrm{~N}^{15} \mathrm{~N}$ isotopologues. A theoretical calculation (Lewis et al. 2008b) has studied the perturbations involving these high-lying Rydberg states. Oscillator strengths and line widths have been obtained from a number of experimental (Stark et al. 2005, 2008; Heays et al. 2009; Huber et al. 2009) and theoretical (Jungen et al. 2003; Haverd et al. 2005; Lavín \& Velasco 2011) efforts. Lifetimes of Rydberg states have been determined through a combination of experiments and calculations (Sprengers et al. 2004; Lewis et al. 2005a,b; Sprengers et al. 2005a; Sprengers \& Ubachs 2006). As for $\mathrm{SO}_{2}$, the focus has been on absorption cross sections at UV wavelengths (Rufus et al. 2003, 2009; Danielache et al. 2008; Hermans et al. 2009; Blackie et al. 2011), where Danielache et al. (2008) studied isotolopogues for sulfur. Furthermore, absorption cross sections for ammonia and its isotopologues (Cheng et al. 2006; Wu et al. 2007) and carbon dioxide (Stark et al. 2007) have been determined experimentally.

Steven R. Federman chair of Working Group

\section{References}

Allen, M. D., Evenson, K. M., \& Brown, J. M. 2004, J. Mol. Spectrosc., 227, 13

Amano, T. \& Hirao, T. 2005, J. Mol. Spectrosc., 233, 7

Amano, T., Hashimoto, K., \& Hirao, T. 2006, J. Mol. Struct., 795, 190

Amano, T. 2008, J. Chem. Phys., 129, 244305

Amano, T. 2010a, ApJ, 716, L1

Amano, T. 2010b, A\&BA, 516, L4

Amano, T. 2010c, J. Mol. Spectrosc., 259, 16 
Andric, L., Bouakline, F., Grozdanov, T. P., \& McCarroll, R. 2004, A\& A, 421, 381

Araki, M., Furuya, T., \& Saito, S. 2001, J. Mol. Spectrosc., 210, 132

Asvany, O., Ricken, O., Müller, H. S. P., Wiedner, M. C., Giesen, T. F., \& Schlemmer, S. 2008, Phys. Rev. Lett., 100, 233004

Bailleux, S., Walters, A., Grigorova, E., \& Margulès, L. 2008, ApJ, 679, 920

Baker, J., 2005a, Chem. Phys. Lett., 408, 312

Baker, J., 2005b, J. Mol. Spectrosc., 234, 75

Baker, J. \& Launay, F. 2005a, Chem. Phys. Lett., 404, 49

Baker, J. \& Launay, F. 2005b, Chem. Phys. Lett., 415, 296

Baker, J. \& Launay, F. 2005c, J. Chem. Phys., 123, 234302

Barber, R. J., Tennyson, J., Harris, G. J., \& Tolchenov, R. N. 2006, MNRAS, 368, 1087

Barinovs, G. \& van Hemert, M. C. 2004, Chem. Phys. Lett., 399, 406

Bauschlicher, C. W., et al. 2010, ApJS, 189, 341. See http://www.astrochem.org/pahdb/

Belloche, A., Menten, K. M., Comito, C., Müller, H. S. P., Schilke, P., Ott, J., Thorwirth, S., \& Hieret, C. 2008, $A \& \mathcal{E} A, 482,179$

Belloche, A., Garrod, R. T., Müller, H. S. P., Menten, K. M., Comito, C., \& Schilke, P. 2009, $A \& A, 499,215$

Ben, J., Li, L., Zheng, L., Chen., Y., \& Yang, X. 2007, Chem. Phys., 335, 109

Bernath, P. F., et al. 2005, Geophys. Res. Lett., 32, L15S01. See http://www.ace.uwaterloo.ca/

Bernath, P. F. 2009, Int. Rev. Phys. Chem., 28, 681

Bernath, P. F. \& Colin, R. 2009, J. Mol. Spectrosc., 257, 20

Bitencourt, A. C. P., Prudente, F. V., \& Vianna, J. D. M. 2007, J. Phys. B., 40, 2075

Bizzocchi, L., Cludi, L., \& Degli Esposti, C. 2003, J. Mol. Spectrosc., 218, 53

Bizzocchi, L., Degli Esposti, C., \& Dore, L. 2006, A\& A, 455, 1161

Bizzocchi, L., Degli Esposti, C., Dore, L., \& Kisiel, Z. 2008, J. Mol. Spectrosc., 251, 138

Blackie, D., Blackwell-Whitehead, R., Stark, G., Pickering, J. C., Smith, P. L., Rufus, J., \& Thorne, A. P. 2011, JGRE, 116, 03006

Borges, I. 2006a, J. Phys. B, 39, 641

Borges, I. 2006b, Chem. Phys., 328, 284

Bornhauser, P., Knopp, G., Gerber, T., \& Radi, P. P. 2010, J. Mol. Spectrosc., 262, 69

Bornhauser, P., Sych, Y., Knopp, G., Gerber, T., \& Radi, P. P. 2011, J. Chem. Phys., 134, 044302

Bouakline, F., Grozdanov, T. P., Andric, L., \& McCarroll, R. 2005, J. Chem. Phys., 122, 044108

Brauer, C. S., Pearson, J. C., Drouin, B. J., \& Yu, S. 2009, ApJS, 184, 133

Brown, J. M., Körsgen, H., Beaton, S. P., \& Evenson, K. M. 2006, J. Chem. Phys., 124, 234309

Brown, J. M. \& Müller, H. S. P. 2009, J. Mol. Spectrosc., 255, 68

Brünken, S., Müller, H. S. P., Lewen, F., \& Winnewisser, G. 2003, Phys. Chem. Chem. Phys., 5,1515

Brünken, S., Müller, H. S. P., Lewen, F., \& Giesen, T. F. 2005, J. Chem. Phys., 123, 164315

Brünken, S., Müller, H. S. P., Thorwirth, S., Lewen, F., \& Winnewisser, G. 2006, J. Mol. Struct., 780,3

Brünken, S., Müller, H. S. P., Endres, C., Lewen, F., Giesen, T., Drouin, B., Pearson, J. C., \& Mäder, H. 2007a, Phys. Chem. Chem. Phys., 9, 2103

Brünken, S., Gottlieb, C. A., Gupta, H., McCarthy, M. C., \& Thaddeus, P. 2007b, A\&A, 464, L33

Brünken, S., Gottlieb, C. A., McCarthy, M. C., \& Thaddeus, P. 2009a, ApJ, 697, 880

Brünken, S., Yu, Z., Gottlieb, C. A., McCarthy, M. C., \& Thaddeus, P. 2009b, ApJ, 706, 1588

Burrows, A., Dulick, M., Bauschlicher, C. W., Bernath, P. F., Ram, R. S., Sharp, C. M., \& Milsom, J. A. 2005, ApJ, 624, 988

Cacciani, P. \& Ubachs, W. 2004, J. Mol. Spectrosc., 225, 62

Cami, J., et al. 2009, ApJ, 690, L122

Cami, J., van Malderen, R., \& Markwick, A. J. 2010a, ApJS, 187, 409. See http://www.spectrafactory.net/

Cami, J., Bernard-Salas, J., Peeters, E., \& Malek, S. E. 2010b, Science, 329, 1180

Caris, M., Lewen, F., Müller, H. S. P., \& Winnewisser, G. 2004, J. Mol. Struct., 695-696, 243 
Caris, M., Giesen, T. F., Duan, C., Müller, H. S. P., Schlemmer, S., \& Yamada, K. M. T. 2009, J. Mol. Spectrosc., 253, 99

Carvajal, M., et al. 2009, A\&A, 500, 1109

Carvajal, M., Kleiner, I., \& Demaison, J. 2010, ApJS, 190, 315

Cazzoli, G. \& Puzzarini, C. 2005, J. Mol. Spectrosc., 233, 280

Cazzoli, G., Puzzarini, C., Tamassia, F., Borri, S., \& Bartalini, S. 2006a, J. Mol. Spectrosc., 235, 265

Cazzoli, G., Cludi, L., \& Puzzarini, C. 2006b, J. Mol. Struct., 780, 260

Cazzoli, G. \& Puzzarini, C. 2006, J. Mol. Spectrosc., 239, 64

Cazzoli, G. \& Puzzarini, C. 2008, A\& A, 487, 1197

Cazzoli, G., Dore, L., Puzzarini, C., \& Gauss, J. 2010a, Mol. Phys., 108, 2335

Cazzoli, G., Cludi, L., Puzzarini, C., \& Gauss, J. 2010b, A\&6A, 509, A1

Chakrabarti, K. \& Tennyson, J. 2006, J. Phys. B., 39, 1485

Chen, C.-W., Merer, A. J., Chao, J.-M., \& Hsu, Y.-C. 2010, J. Mol. Spectrosc., 263, 56

Chen, K.-S., Zhang, G., Merer, A. J., Hsu, J.-C., \& Chen, W.-J. 2011, J. Mol. Spectrosc., 267, 169

Cheng, B.-M., Chung, C.-Y., Bahou. M., Lee, Y.-P., Lee, L. C., van Harrevelt, R., \& van Hemert, M. C. 2004, J. Chem. Phys., 120, 224

Cheng, B.-M., et al. 2006, ApJ, 647, 1535

Chowdhury, P. K., Merer, A. J., Rixon, S. J., Bernath, P. F., \& Ram, R. S. 2006, Phys. Chem. Chem. Phys., 8, 822

Christen, D. \& Müller, H. S. P. 2003, Phys. Chem. Chem. Phys., 5, 3600

Colin, R. \& Bernath, P. F. 2010, J. Mol. Spectrosc., 263, 120

Cushing, M. C., et al. 2011, ApJ, accepted, arXiv:1108.4678

Danielache, S. O., Eskebjerg, C., Johnson, M. S., Ueno, Y., \& Yoshida, N. 2008, JGRD, 113, 17314

Demyk, K., et al. 2007, A\&A A, 466, 255

Dickenson, G. D., Nortje, A. C., Steenkamp, C. M., Rohwer, E. G., \& du Plessis, A. 2010, ApJ, 714, L268

Dore, L., Bizzocchi, L., Degli Esposti, C., \& Tinti, F. 2009, A\& A, 496, 275

Dore, L., Bizzocchi, L., Degli Esposti, C., \& Gauss, J. 2010, J. Mol. Spectrosc., 263, 44

Drouin, B. J., Pearson, J. C., Walters, A., \& Lattanzi, V. 2006, J. Mol. Spectrosc., 240, 227

Drouin, B. J., Yu, S., Pearson, J. C., \& Müller, H. S. P. 2009, JQSRT, 110, 2077

du Plessis, A., Rohwer, E. G., \& Steenkamp, C. M. 2006, ApJS, 165, 432

du Plessis, A., Rohwer, E. G., \& Steenkamp, C. M. 2007, J. Mol. Spectrosc., 243, 124

Duan, Y.-B., Ozier, I., Tsunekawa, S., \& Takagi, K. 2003, J. Mol. Spectrosc., 218, 95

Dubernet, M. L., Boudon, V., Culhane, J. L., et al. 2010, JQSRT, 111, 2151

Dulick, M., Bauschlicher, C. W., Burrows, A., Sharp, C. M., Sharp, R. S., Ram, R. S., \& Bernath, P. F. 2003, ApJ, 594, 651

Eidelsberg, M. \& Rostas, F. 2003, ApJS, 145, 89

Eidelsberg, M., Launay, F., Ito, K., Matsui, T., Hinnen, P. C., Reinhold, E., Ubachs, W., \& Huber, K. P. 2004a, J. Chem. Phys., 121, 292

Eidelsberg, M. Lemaire, J. L., Fillion, J. H., Rostas, F., Federman, S. R., \& Sheffer, Y. 2004b, $A \& A, 424,355$

Eidelsberg, M., Sheffer, Y., Federman, S. R., Lemaire, J. L., Fillion, J. H., Rostas, F., \& Ruiz, J. 2006, ApJ, 647, 1543

Elkeurti, M., Coudert, L. H., Orphal, J., Wlodarczak, G., Fellows, C. E., \& Toumi, S. 2008, J. Mol. Spectrosc., 251, 90

Endres, C. P., Müller, H. S. P., Brünken, S., Paveliev, D. G., Giesen, T. F., Schlemmer, S., \& Lewen, F. 2006, J. Mol. Struct., 795, 242

Endres, C. P., Drouin, B. J., Pearson, J. C., Müller, H. S. P., Lewen, F., Schlemmer, S., \& Giesen, T. F. 2009, A\&BA, 504, 635

Fillion, J.-H., Ruiz, J., Yang, X.-F., Castillejo, M., Rostas, F., \& Lemaire, J.-L. 2004, J. Chem. Phys., 120, 6531 
Fisher, J., Paciga, G., Xu, L.-H., Zhao, S. B., Moruzzi, G., \& Lees, R. M. 2007, J. Mol. Spectrosc., 245,7

Flores-Mijangos, J., Brown, J. M., Matsushima, F., Odashima, H., Takagi, K., Zink, L. R., \& Evenson, K. M. 2004, J. Mol. Spectrosc., 225, 189

Flory, M. A., Halfen, D. T., \& Ziurys, L M. 2004, J. Chem. Phys., 121, 8385

Flory, M. A., McLamarrah, S. K., \& Ziurys, L. M. 2006, J. Chem. Phys., 125, 194304

Flory, M. A. \& Ziurys, L. M. 2008, J. Mol. Spectrosc., 247, 76

Fortman, S. M., Medvedev, I. R., Neese, C. F., \& De Lucia, F. C. 2010, ApJ, 725, 1682

Fortman, S. M., Medvedev, I. R., Neese, C. F., \& De Lucia, F. C. 2011, ApJ, 737, 20

Fujimori, R., Kawaguchi, K., \& Amano, T. 2011, ApJ, 729, L2

Galué, H. A., Rice, C. A., Steill, J. D., \& Oomens, J. 2011, J. Chem. Phys., 134, 054310

Gendriesch, R., Lewen, F., Klapper, G., Menten, K. M., Winnewisser, G., Coxon, J. A., \& Müller, H. S. P. 2009, A\&\&A, 497, 927

Gilijamse, J. J., Hoekstra, S., Meek, S. A., Metsälä, M., van de Meerakker, S. Y. T., Meijer, G., \& Groenenboom, G. C. 2007, J. Chem. Phys., 127, 221102

Golubiatnikov, G. Y., Markov, V. N., Guarnieri, A., \& Knöchel, R. 2006, J. Mol. Spectrosc., 240,251

Gottlieb, C. A., Brünken, S., McCarthy, M. C., \& Thaddeus, P. 2007, J. Chem. Phys., 126, 191101

Gottlieb, C. A., McCarthy, M. C., \& Thaddeus, P. 2010, ApJS, 189, 261

Groner, P., Medvedev, I. R., De Lucia, F. C., \& Drouin, B. J. 2008, J. Mol. Spectrosc., 251, 180

Grozdanov, T. P., Bouakline, F., Andric, L., \& McCarroll, R. 2004, J. Phys. B., 37, 1737

Gupta, H., Brünken, S., Tamassia, F., Gottlieb, C. A., McCarthy, M. C., \& Thaddeus, P. 2007, ApJ, 655, L57

Hakalla, R., Kepa, R., Szajna, W., \& Zachwieja, M. 2006, Eur. Phys. J. D, 38, 481

Halfen, D. T. \& Ziurys, L. M. 2004, ApJ, 607, L63

Halfen, D. T. \& Ziurys, L. M. 2008, ApJ, 672, L77

Halfen, D. T., Ziurys, L. M., Pearson, J. C., \& Drouin, B. J. 2008, ApJ, 687, 731

Halfen, D. T., Sun, M., Clouthier, D. J., \& Ziurys, L. M. 2009a, J. Chem. Phys., 130, 014305

Halfen, D. T., Ziurys, L. M., \& Brown, J. M. 2009b, J. Chem. Phys., 130, 164301

Hargreaves, R. J., Li, G., \& Bernath, P. F. 2011, ApJ, 735, 111

Harrison, J. J. \& Brown, J. M. 2008, ApJ, 686, 1426

Harrison, J. J., Brown, J. M., Halfen, D. T., \& Ziurys, L. M. 2006, ApJ, 637, 1143

Harrison, J. J., Brown, J. M., Flory, M. A., Sheridan, P. M., McLamarrah, S. K., \& Ziurys, L. M. 2007, J. Chem. Phys., 127, 194308

Harrison, J. J., Brown, J. M., Chen., J., Steimle, T. C., \& Sears, T. J. 2008, ApJ, 679, 854

Hase, F., Wallace, L., McLeod, S. D., Harrison, J. J., \& Bernath, P. F. 2010, JQSRT, 111, 521. See http://www.ace.uwaterloo.ca/solaratlas.html/

Haverd, V. E., Lewis, B. R., Gibson, S. T., \& Stark, G. 2005, J. Chem. Phys., 123, 214304

Heays, A. N., Lewis, B. R., Stark, G., Yoshino, K., Smith, P. L., Huber, K. P., \& Ito, K. 2009, J. Chem. Phys., 131, 194308

Hermans, C., Vandaele, A. C., \& Fally, S. 2009, JQSRT, 110, 756

Hirata, Y., Kubota, S., Watanabe, S., Momose, T., \& Kawaguchi, K. 2008, J. Mol. Spectrosc., 251,314

Huang, X., Schwenke, D. W., \& Lee, T. J. 2011, J. Chem. Phys., 134, 044320 and 044321

Huber, K. P., Chan, M.-C., Stark, G., Ito, K., \& Matsui, T. 2009, J. Chem. Phys., 131, 084301

Hübers, H.-W., Evenson, K. M., Hill, C., \& Brown, J. M. 2009, J. Chem. Phys., 131, 034311

Hudgins, D. M., Bauschlicher, C. W., \& Allamandola, L. J. 2005, ApJ, 632, 316

Iglesias-Groth, S., Cataldo, F., \& Manchado, A. 2011, MNRAS, 413, 213

Ilyushin, V. V., Alekseev, E. A., Dyubko, S. F., Kleiner, I., \& Hougen, J. T. 2004, J. Mol. Spectrosc., 227, 115

Ilyushin, V. V., Alekseev, E. A., Dyubko, S. F., Motiyenko, R. A., \& Lovas, F. J. 2005, J. Mol. Spectrosc., 231, 15

Ilyushin, V. \& Lovas, F. J. 2007, J. Phys. Chem. Ref. Data, 36, 1141

Ilyushin, V., Kleiner, I., \& Lovas, F. J. 2008, J. Phys. Chem. Ref. Data, 37, 97 
Ilyushin, V., Kryvda, A., \& Alekseev, E. 2009, J. Mol. Spectrosc., 255, 32

Jacquinet-Husson, N., Crepeau, L., Armante, R., et al. 2011, JQSRT, 112, 2395

Jansen, P., Xu, L.-H., Kleiner, I., Ubachs, W., \& Bethlem, H. L. 2011, Phys. Rev. Lett., 106, 100801

Joblin, C. \& Tielens, A. G. G. M. (Eds.) 2011, EAS Publications Series, Vol. 46

Joester, J. A., Nakajima, M., Reilly, N. J., Kokkin, D. L., Nauta, K., Kable, S. H., \& Schmidt, T. W. 2007, J. Chem. Phys., 127, 214303

Jungen, Ch., Huber, K. P., Jungen, M., \& Stark, G. 2003, J. Chem. Phys., 118, 4517

Kania, P., Hermanns, M., Brünken, S., Müller, H. S. P., \& Giesen, T. F. 2011, J. Mol. Spectrosc., 268,173

Kassi, S. \& Campargue, A. 2011, J. Mol. Spectrosc., 267, 36

Kawaguchi, K., Kasai, Y., Ishikawa, S.-I., \& Kaifu, N. 1995, PASJ, 47, 853

Kawahara, H., Kato, H., Hoshino, M., Tanaka, H., \& Brunger, M. J. 2008, Phys. Rev., A77, 012713

Killian, T. C., Gottlieb, C. A., \& Thaddeus, P. 2007, J. Chem. Phys., 127, 114320

Kisiel, Z., Pszczółkowski, L., Drouin, B. J., Brauer, C. S., Yu, S., \& Pearson, J. C. 2009, J. Mol. Spectrosc., 258, 26

Kisiel, Z., et al. 2010, Phys. Chem. Chem. Phys., 12, 8329

Kokkin, D. L., Bacskay, G. B., \& Schmidt, T. W. 2007, J. Chem. Phys., 126, 084302

Kryvda, A. V., Gerasimov, V. G., Dyubko, S. F., Alekseev, E. A., \& Motiyenko, R. A. 2009, J. Mol. Spectrosc., 254, 28

Lattanzi, V., Walters, A., Drouin, B. J., \& Pearson, J. C. 2008, ApJS, 176, 536

Lattanzi, V., Gottlieb, C. A., Thaddeus, P., Thorwirth, S., \& McCarthy, M. C. 2010, ApJ, 720, 1717

Lauvergnat, D., Coudert, L. H., Klee, S., \& Smirnov, M. 2009, J. Mol. Spectrosc., 256, 204

Lavín, C., Velasco, A. M., \& Martín, I. 2009, ApJ, 692, 1354

Lavín, C. \& Velasco, A. M. 2011, ApJ, 739, 16

Lefebvre-Brion, H. \& Lewis, B. R., 2007, Mol. Phys., 105, 1625

Lefebvre-Brion, H., Liebermann, H. P., \& Vázquez, G. J. 2010, J. Chem. Phys., 132, 024311

Levshakov, S. A., Kozlov, M. G., \& Reimers, D. 2011, ApJ, 738, 26

Lewis, B. R., Gibson, S. T., Zhang, W., Lefebvre-Brion, H., \& Robbe, J.-M. 2005a, J. Chem. Phys., 122, 144302

Lewis, B. R., Gibson, S. T., Sprengers, J. P., Ubachs, W., Johansson, A., \& Wahlström, C.-G. 2005b, J. Chem. Phys., 123, 236101

Lewis, B. R., Baldwin, K. G. H., Sprengers, J. P., Ubachs, W., Stark, G., \& Yoshino, K. 2008a, J. Chem. Phys., 129, 164305

Lewis, B. R., Heays, A. N., Gibson, S. T., Lefebvre-Brion, H., \& Lefebvre, R. 2008b, J. Chem. Phys., 129, 164306

Li, G., Gordon, I. E., Bernath, P. F., \& Rothman, L. S. 2011, JQSRT, 112, 1543

Li, W.-B., Zhu, L.-F., Yuan, Z.-S., Liu, X.-J., \& Xu, K.-Z. 2006, J. Chem. Phys., 125, 154310

Livingston, W. \& Wallace, L. 2003, An Atlas of the Solar Spectrum in the Infrared from 1850 $-9000 \mathrm{~cm}^{-1}$ (1.1 to $\left.5.4 \mu \mathrm{m}\right)$, Revised, N.S.O. Technical Report \# 03-001, National Solar

Observatory, Tucson. See ftp://nsokp.nso.edu/pub/atlas/photatl/

Lovas, F. J. 2004, J. Phys. Chem. Ref. Data, 33, 177

Lovas, F. J. \& Groner, P. 2006, J. Mol. Spectrosc., 236, 173

Lovas, F. J., Plusquellic, D. F., Pate, B. H., Neill, J. L., Muckle, M. T., \& Remijan, A. J. 2009, J. Mol. Spectrosc., 257, 82

Maeda, A., Hirao, T., Bernath, P. F., \& Amano, T. 2001, J. Mol. Spectrosc., 210, 250

Maeda, A., et al. 2008, ApJS, 176, 543

Margulès, L., Lewen, F., Winnewisser, G., Botschwina, P., \& Müller, H. S. P. 2003, Phys. Chem. Chem. Phys., 5, 2770

Margulès, L., Coudert, L. H., Møllendal, H., Guillemin, J.-C., Huet, T. R., \& Janečkovà, R. 2009a, J. Mol. Spectrosc., 254, 55

Margulès, L., et al. 2009b, A\&\&A, 493, 565

Margulès, L., et al. 2010, ApJ, 714, 1120 
McCall, B. J., Casaes, R. N., Ádámkovics, M., \& Saykally, R. J. 2003, Chem. Phys. Lett., 374, 583

McCarthy, M. C. \& Thaddeus, P. 2005, J. Chem. Phys., 122, 174308

McCarthy, M. C., Gottlieb, C. A., Gupta, H., \& Thaddeus, P. 2006, ApJ, 652, L141

McLamarrah, S. K., Sheridan, P. M., \& Ziurys, L. M. 2005, Chem. Phys. Lett., 414, 301

Medvedev, I. R., De Lucia, F. C., \& Herbst, E. 2009, ApJS, 181, 433

Mladenović, M., Lewerenz, M., McCarthy, M. C., \& Thaddeus, P. 2009, J. Chem. Phys., 131, 174308

Mota, R., et al. 2005, Chem. Phys. Lett., 416, 152

Mukhopadhyay, I., Perry, D. S., Duan, Y.-B., Pearson, J. C., Albert, S., Butler, R. A. H., Herbst, E., \& De Lucia, F. C. 2002, J. Chem. Phys., 116, 3710

Müller, H. S. P. \& Christen, D. 2004, J. Mol. Spectrosc., 228, 298

Müller, H. S. P., Menten, K. M., \& Mäder, H. 2004, A\&SA, 428, 1019

Müller, H. S. P. \& Brünken, S. 2005, J. Mol. Spectrosc., 232, 213

Müller, H. S. P., Schlöder, F., Stutzki, J., \& Winnewisser, G. 2005, J. Mol. Struct., 742, 215

Müller, H. S. P., et al. 2007, Phys. Chem. Chem. Phys., 9, 1579

Müller, H. S. P., Drouin, B. J., \& Pearson, J. C. 2009, A\&̇A, 506, 1487

Müller, H. S. P., Dong, F., Nesbitt, D. J., Furuya, T., \& Saito, S. 2010, Phys. Chem. Chem. Phys., 12, 8362

Müller, H. S. P. 2010, $A \mho A, 514$, L6

Müller, H. S. P., Coutens, A., Walters, A., Grabow, J.-U., \& Schlemmer, S. 2011, J. Mol. Spectrosc., 267, 100

Nakajima, M., Joester, J. A., Page, N. I., Reilly, N. J., Bacskay, G. B., Schmidt, T. W., \& Kable, S. H. 2009, J. Chem. Phys., 131, 044301

Nassar, R. \& Bernath, P. F. 2003, JQSRT, 82, 279

Nemes, L. et al. 1994, Chem. Phys. Lett., 218, 295

Ozeki, H., Bailleux, S., \& Wlodarczak, G. 2011, A\&A, 527, A64

Pearson, J. C. \& Drouin, B. J. 2006, ApJ, 647, L83

Pearson, J. C., Brauer, C. S., \& Drouin, B. J. 2008, J. Mol. Spectrosc., 251, 394

Pearson, J. C., Brauer, C. S., Drouin, B. J., \& Xu, L.-H. 2009, Can. J. Phys., 87, 449

Plusquellic, D. F., Lovas, F. J., Pate, B. H., Neill, J. L., Muckle, M. T., \& Remijan, A. J. 2009, J. Phys. Chem. A, 1131, 12911

Polehampton, E. T., Brown, J. M., Swinyard, B. M., \& Baluteau, J.-P. 2003, A\&A, 406, L47

Puzzarini, C., Dore, L., \& Cazzoli, G. 2003, J. Mol. Spectrosc., 217, 19

Puzzarini, C., Cazzoli, G., Harding, M. E., Vázquez, J., \& Gauss, J. 2009, J. Chem. Phys., 131, 234304

Ram, R. S., Davis, S. P., Wallace, L., Engleman, R., Appadoo, D. R. T., \& Bernath, P. F. 2006, J. Mol. Spectrosc., 237, 225

Ram, R. S. \& Bernath, P. F. 2010, J. Mol. Spectrosc., 260, 115

Ram, R. S., Wallace, L., \& Bernath, P. F. 2010b, J. Mol. Spectrosc., 263, 82

Ram, R. S., Wallace, L., Hinkle, K., \& Bernath, P. F. 2010c, ApJS, 188, 500

Ram, R. S. \& Bernath, P. F. 2011a, ApJS, 194, 34

Ram, R. S., Tereszchuk, K., Gordon, I. E., Walker, K. A., \& Bernath, P. F. 2011b, J. Mol. Spectrosc., 266, 86

Ricks, A. M., Douberly, G. E., \& Duncan, M. A. 2009, ApJ, 702, 301

Rothman, L. S., et al. 2009, JQSRT, 110, 523. See http://www.cfa.harvard.edu/HITRAN/

Rothman, L. S., et al. 2010, JQSRT, 111, 2139

Rufus, J., Stark, G., Smith, P. L., Pickering, J. C., \& Thorne, A. P. 2003, JGRE, 108, 5011

Rufus, J., Stark, G., Thorne, A. P., Pickering, J. C., Blackwell-Whitehead, R. J., Blackie, D., \& Smith, P. L. 2009, JGRE, 114, 06003

Savin, D. W., et al. 2011, Prog. Phys., in press

Schmidt, T. W. \& Bacskay, G. B. 2007, J. Chem. Phys., 127, 234310

Sharpe, S. W., Johnson, T. J., Sams, R. L., Chu, P. M., Rhoderick, G. C., \& Johnson, P. A. 2004, Appl. Spectrosc., 58, 1452. See http://nwir.pnl.gov/

Shayesteh, A. \& Bernath, P. F. 2011, J. Chem. Phys., 135, 094308 
Shayesteh, A., Tereszchuk, K., Bernath, P. F., \& Colin, R. 2003a, J. Chem. Phys., 118, 1158

Shayesteh, A., Tereszchuk, K., Bernath, P. F., \& Colin, R. 2003b, J. Chem. Phys., 118, 3622

Shayesteh, A., Appadoo, D. R. T., Gordon, I., \& Bernath, P. F. 2003c, J. Chem. Phys., 119, 7785

Shayesteh, A., Appadoo, D. R. T., Gordon, I., LeRoy, R. J., \& Bernath, P. F. 2004a, J. Chem. Phys., 120, 10002

Shayesteh, A., Walker, K. A., Gordon, I., Appadoo, D. R. T., \& Bernath, P. F. 2004b, J. Mol. Struct., 695-696, 23

Shayesteh, A., Henderson, R. D. E., Le Roy, R. J., \& Bernath, P. F. 2007, J. Phys. Chem. A, 111,12495

Sheffer, Y., Federman, S. R., \& Andersson, B.-G. 2003, ApJ, 597, L29

Sheffer, Y. \& Federman, S. R. 2007, ApJ, 659, 1352

Sheridan, P. M. \& Ziurys, L. M. 2003, J. Chem. Phys., 118, 6370

Sheridan, P. M., McLamarrah, S. K., \& Ziurys, L. M. 2003, J. Chem. Phys., 119, 9496

Sheridan, P. M., Flory, M. A., \& Ziurys, L. M. 2004, J. Chem. Phys., 121, 8360

Shi, D., Liu, H., Zhang, X., Sun, J., Zhu, Z., \& Liu, Y. 2010, J. Mol. Struct., 956, 10

Sprengers, J. P., Ubachs, W., Baldwin, K. G. H., Lewis, B. R., \& Tchang-Brillet, W-ÜL. 2003, J. Chem. Phys., 119, 3160

Sprengers, J. P., Johansson, A., L'Huillier, A., Wahlström, C.-G., Lewis, B. R., \& Ubachs, W. 2004, Chem. Phys. Lett., 389, 348

Sprengers, J. P., Ubachs, W., \& Baldwin, K. G. H. 2005a, J. Chem. Phys., 122, 144301

Sprengers, J. P., Reinhold, E., Ubachs, W., Baldwin, K. G. H., \& Lewis, B. R. 2005b, J. Chem. Phys., 123, 144315

Sprengers, J. P. \& Ubachs, W. 2009, J. Mol. Spectrosc., 235, 176

Stark, G., Huber, K. P., Yoshino, K., Smith, P. L., \& Ito, K. 2005, J. Chem. Phys., 123, 214303

Stark, G., Yoshino, K., Smith, P. L., \& Ito, K. 2007, JQSRT, 103, 67

Stark, G., Lewis, B. R., Heays, A. N., Yoshino, K., Smith, P. L., \& Ito, K. 2008, J. Chem. Phys., 128,114302

Steinmann, C. M., Rohwer, E. G., \& Stafast, H. 2003, ApJ, 590, L123; errat. ApJ, 591, L167

Sumiyoshi, Y., Ueno, T., \& Endo, Y. 2003, J. Chem. Phys., 119, 1426

Tanabashi, A., Hirao, T., Amano, T., \& Bernath, P. F. 2005, ApJ, 624, 1116

Tanabashi, A., Hirao, T., Amano, T., \& Bernath, P. F. 2007, ApJS, 169, 472

Tashkun, S. A. \& Perevalov, V. I. 2011, JQSRT, 112, 1403

Tenenbaum, E. D., Flory, M. A., Pulliam, R. L., \& Ziurys, L. M. 2007, J. Mol. Spectrosc., 244, 153

Thaddeus, P., Gottlieb, C. A., Gupta, H., Brünken, S., McCarthy, M. C., Agúndez, M., Guélin, M., \& Cernicharo, J. 2008, ApJ, 677, 1132

Thorn, P. A., et al. 2007, J. Chem. Phys., 126, 064306

Tinti, F., Bizzocchi, L., Degli Esposti, C., \& Dore, L. 2007, ApJ, 669, L113

Toffoli, D. \& Lucchese, R. R. 2004, J. Chem. Phys., 120, 6010

Vázquez, G. J., Amero, J. M., Liebermann, H. P., Buenker, R. J., \& Lefebvre-Brion, H. 2007, J. Chem. Phys., 126, 164302

Vázquez, G. J., Amero, J. M., Liebermann, H. P., \& Lefebvre-Brion, H. 2009, J. Phys. Chem. A, 113,13395

Vieitez, M. O., Ivanov, T. I., de Lange, C. A., Ubachs, W., Heays, A. N., Lewis, B. R., \& Stark, G. 2008, J. Chem. Phys., 128, 134313

Wallace, L., Hinkle, K., \& Livingston, W. C. 2001, Sunspot Umbral Spectra in the Region 4000 to $8640 \mathrm{~cm}^{-1}$ (1.16 to $\left.2.50 \mu \mathrm{m}\right)$, N.S.O. Technical Report \# 01-001, National Solar Observatory, Tucson. See ftp://nsokp.nso.edu/pub/atlas/spot5atl/

Wallace, L., Hinkle, K., \& Livingston, W. C. 2002, Sunspot Umbral Spectra in the Regions 1925 to 2226 and 2392 to $3480 \mathrm{~cm}^{-1}$ (2.87 to 4.18 and 4.48 to $5.35 \mu \mathrm{m}$ ), N.S.O. Technical Report \# 02-001, National Solar Observatory, Tucson. See ftp://nsokp.nso.edu/pub/atlas/spot6atl/

Walters, A., Müller, H. S. P., Lewen, F., \& Schlemmer, S. 2009, J. Mol. Spectrosc., 257, 24

Watson, J. K. G. 2001, ApJ, 555, 472 
Weselak, T., Galazutdinov, G. A., Musaev, F. A., Beletsky, Y., \& Krelowski, J. 2009, A 8 A, 495, 189

Wu, Y.-J., Lu, H.-C., Chen, H.-K., Cheng, B.-M., Lee, Y.-P., \& Lee, L. C. 2007, J. Chem. Phys., 127,154311

Xu, L.-H., et al. 2008, J. Mol. Spectrosc., 251, 305

Yang, X., Ben, J., Li, L., \& Chen, Y. 2008, JQSRT, 109, 468

Yonezu, T., Matsushima, F., Moriwaki, Y., Takagi, K., \& Amano, T. 2009, J. Mol. Spectrosc., 256,238

Yoshikawa, T., Sumiyoshi, Y., \& Endo, Y. 2009a, J. Chem. Phys., 130, 094302

Yoshikawa, T., Sumiyoshi, Y., \& Endo, Y. 2009b, J. Chem. Phys., 130, 164303

Yu, S., Drouin, B. J., Pearson, J. C., \& Pickett, H. M. 2009, ApJS, 180, 119

Yu, S., et al. 2010, J. Chem. Phys., 133, 174317

Yurchenko, S. N., Barber, R. J., \& Tennyson, J. 2011, MNRAS 413, 1828

Zack, L. N., Pulliam, R. L., \& Ziurys, L. M. 2009, J. Mol. Spectrosc., 256, 186

Zelinger, Z., Amano, T., Ahrens, V., Brünken, S., Lewen, F., Müller, H. S. P., \& Winnewisser, G. 2003, J. Mol. Spectrosc., 220, 223

Zhang, G., Chen, K.-S., Merer, A. J., Hsu, Y.-C., Chen, W.-J., Shaji, S., \& Liao, Y.-A. 2005, J. Chem. Phys., 122, 244308

Zobov, N. F., et al. 2008, MNRAS, 387, 1093 